\title{
Overcoming the Design Challenge in 3D Biomimetic Hybrid Scaffolds for Bone and Osteochondral Regeneration by Factorial Design
}

\author{
Alessandra Dellaquila, Elisabetta Campodoni, Anna Tampieri and Monica Sandri* \\ Institute of Science and Technology for Ceramics, National Research Council of Italy (ISTEC-CNR), Faenza, Italy
}

\section{OPEN ACCESS}

Edited by:

Francesca Taraballi,

Houston Methodist Research Institute, United States

Reviewed by: Wenguo Cui,

Shanghai Jiao Tong University, China Tiziano Serra,

AO Research Institute, Switzerland

${ }^{*}$ Correspondence: Monica Sandri monica.sandri@istec.cnr.it

Specialty section: This article was submitted to Biomaterials,

a section of the journal Frontiers in Bioengineering and Biotechnology

Received: 09 April 2020 Accepted: 10 June 2020 Published: 07 July 2020

Citation:

Dellaquila A, Campodoni $E$ Tampieri A and Sandri M (2020) Overcoming the Design Challenge in 3D Biomimetic Hybrid Scaffolds

for Bone and Osteochondral Regeneration by Factorial Design. Front. Bioeng. Biotechnol. 8:743. doi: 10.3389/fbioe.2020.00743
Scaffolds for bone regeneration have been engineered by a plethora of manufacturing technologies and biomaterials. However, the performance of these systems is often limited by lack of robustness in the process design, that hampers their scalability to clinical application. In the present study, Design of Experiment (DoE) was used as statistical tool to design the biofabrication of hybrid hydroxyapatite $(\mathrm{HA}) /$ collagen scaffolds for bone regeneration and optimize their integration in a multilayer osteochondral device. The scaffolds were synthesized via a multi-step bioinspired process consisting in HA nano-crystals nucleation on the collagen selfassembling fibers and ribose glycation was used as collagen cross-linking method to modulate the mechanical and physical properties. The process design was performed by selecting hydrogel concentration, HA/collagen ratio and cross-linker content as key variables and the fabrication was carried out basing on a full factorial design. Scaffold performances were tested by evaluating porosity, swelling ratio, degradation rate and mechanical behavior as model output responses while physicochemical properties of the constructs were evaluated by TGA, ICP, FT-IR spectroscopy, and XRD analysis. Physicochemical characterizations confirmed the nucleation of a biomimetic inorganic phase and the interaction of the HA and collagenic components. The DoE model revealed a significant interaction between HA content and collagen cross-linking in determining porosity, swelling and mechanical properties of the scaffolds. The combined effect of hydrogel concentration and mineral phase played a key role on porosity and swelling while degradation resulted to be mainly affected by the HA loading and ribose content. The model was then used to determine the suitable input parameters for the synthesis of multi-layer scaffolds with graded mineralization rate, that can be used to mimic the whole cartilage-bone interface. This work proved that experimental design applied to complex biofabrication processes represents an effective and reliable way to design hybrid constructs with standardized and tunable properties for osteochondral tissue engineering.

Keywords: factorial design, osteochondral regeneration, hybrid scaffold, biomineralization, collagen crosslinking 


\section{INTRODUCTION}

In the last decades, scaffolds for bone and osteochondral tissue engineering have been studied by using a wide range of materials and manufacturing technologies (Porter et al., 2009; O'Brien, 2011; Hutmacher et al., 2015).

The osteochondral area is a complex multi-layered region composed of articular cartilage and subchondral bone: the articular cartilage is composed of organic and mineralized hybrid layers, separated by an interface called tidemark (Sophia Fox et al., 2009; Simon and Jackson, 2018). The articular extracellular matrix is mainly composed of water (up to $85 \%$ of the total weight), collagen and proteoglycans while the tidemark and the calcified cartilage are mineralized regions characterized by a graded increase of the inorganic phase content from 25 to 65 wt. \% (Hoemann et al., 2012; Zhang et al., 2012). The inorganic ratio further increases in the bone matrix (65-85 wt. \%), where the major mineral phase is a calcium-deficient multi-substituted apatite and collagen is the main organic constituent (Rey et al., 2009; Tampieri et al., 2011).

The bone matrix has been largely replicated in vitro by using calcium phosphates (CaPs) as inorganic constituents, mainly hydroxyapatite (HA) and tri-calcium phosphate (TCP), due to their biomimetic properties along with polymeric and hybrid materials (Sabir et al., 2009; Iaquinta et al., 2019; Lei et al., 2019) while scaffolds for cartilage repair are usually made of natural or synthetic polymers (Bhattacharjee et al., 2015; Armiento et al., 2018). The regeneration of the whole osteochondral region is conventionally mimicked by combining these scaffolds into bi or trilayer devices, characterized by inorganic phase gradient, graded mechanical properties and different materials, eventually loaded with growth factors for supporting simultaneous cartilage and bone regeneration (Tampieri et al., 2008; Li et al., 2015; Bittner et al., 2019). Levingstone et al. (2014) fabricated a three-layered osteochondral graft in which the cartilage region was composed of collagen and hyaluronan while the middle and bone layers were produced by adding HA powder to a collagen slurry. In another study, a scaffold for osteochondral regeneration was $3 \mathrm{D}$ bioprinted by combining a gradient of nanoHA and poly(lactic-co-glycolic acid) (PLGA) nanospheres incapsulated with chondrogenic transforming growth-factor, demonstrating good osteochondral differentiation in vitro (Castro et al., 2015).

The use of biomimetic mineralization methods, consisting of simultaneous and direct nucleation of HA nano-crystals onto self-assembling collagen type I fibrils, represents a solid strategy to closely mimic the chemical, physical and architectural properties of native bone at molecular level (Tampieri et al., 2003; Qiu et al., 2015). The further incorporation of ions, such as magnesium $\left(\mathrm{Mg}^{2+}\right)$, within the HA lattice ensures the nucleation of a highly biomimetic inorganic phase with low crystallinity and enhanced osteoconductive properties (Minardi et al., 2015; Giorgi et al., 2017; Menale et al., 2019).

However, one of the current limitations of hybrid HA/collagen scaffolds is the lack of physiologically relevant mechanical behavior, mainly due to collagen fast degradation and low mechanical stability. A current approach for addressing this drawback is the use of collagen cross-linking methods (Rault et al., 1996; Krishnakumar et al., 2018); among them, nonenzymatic glycation of collagen by ribose enables the stabilization of the collagen matrix while ensuring biocompatibility, low cytotoxicity and non-immunogenic responses (Brodsky et al., 1990; Tampieri et al., 2005; Eleswarapu et al., 2011; Shankar et al., 2017). Ribose has been successfully used for collagen cross-linking for both cartilage and bone tissue engineering. Hybrid mineralized MgHA/collagen scaffolds cross-linked with ribose have shown increased enzymatic resistivity and high citocompatibility (Gostynska et al., 2017; Krishnakumar et al., 2017) and ribose-glycated collagen gels for cartilage regeneration were used to enhance chondrocytes matrix assembly with no cytotoxic effects (Roy et al., 2008).

Despite the significant progresses of tissue engineering in developing new materials and technologies, the clinical translation is still hampered by a lack of standardization in biomedical research. The design and production of biomaterials for regenerative medicine still remains a challenging costly and time-consuming process because of complex native tissues architecture and laborious implementation, that hinder the scaleup toward their clinical application (Holzapfel et al., 2013; Sadtler et al., 2016). A precise control and tuning of the process parameters via reliable statistical methods and a clear understanding of their role on scaffold properties is essential to have robust and scalable devices (Ratner, 2013; Chen et al., 2020). Compared to conventional design approaches, such as one-variable-at-a-time and trial and error methods, design of experiment (DoE) represents a useful tool to model complex systems as it allows researchers to reduce experiment costs, time and variability by enabling complete data analysis, optimization and outcome prediction (Mason et al., 2003; Leardi, 2009; Dean et al., 2017; Montgomery, 2017).

In the present study, ribose cross-linked magnesium doped HA/collagen scaffolds were synthesized and characterized by TGA, IPC, FT-IR and their performances were systematically investigated by full factorial DoE design. Scaffold porosity, swelling, degradation and mechanical properties in simulated physiological conditions were studied as output responses to the variation of the synthesis parameters. The experimental data were used to build a statistical model of the fabrication process and to optimize the input parameters to mimic different mineralized tissue layers of the osteochondral site.

\section{MATERIALS AND METHODS}

\section{Chemicals}

$\mathrm{HA} /$ collagen scaffolds were synthesized by using type I collagen from equine tendon (Opocrin Spa, Italy) as polymeric phase. Phosphoric acid $\left(\mathrm{H}_{3} \mathrm{PO}_{4}\right.$, purity 85 wt. \%), calcium hydroxide $\left[\mathrm{Ca}(\mathrm{OH})_{2}\right.$, purity 95 wt. \%], magnesium chloride hexahydrate $\left(\mathrm{MgCl}_{2} \cdot 6 \mathrm{H}_{2} \mathrm{O}\right.$, purity 99 wt. \%), ribose $\left(\mathrm{C}_{5} \mathrm{H}_{10} \mathrm{O}_{5}\right.$, purity 99 wt. $\%)$, ethanol (C2H6O, purity 95wt. \%) and sodium azide $\left(\mathrm{NaN}_{3}\right.$, purity 99\%) were obtained from Sigma Aldrich (United States). Phosphate buffer saline (PBS, $\mathrm{pH}$ 7.4) was purchased from EuroClone (Italy). 


\section{Factorial Design}

Scaffolds were produced following a $2^{3}$ full factorial design, which provides for the analysis of three independent factors, each of them at two levels, respectively a low and a high level, and requires a number of trials to be performed equal to $2^{3}$ $=8$ at full resolution, thus eight different scaffold formulations (Table 1; Montgomery and Runger, 2003). The model enables the study of linear influence of each main factor on scaffold properties and the analysis of factors interaction. Preliminary studies were performed to choose the factor levels and to standardize the synthesis protocol, reducing the sources of variation (data not shown).

Three main factors were selected: filtration time $\left(\mathrm{t}, X_{1}\right)$, mineralization rate $\left(\mathrm{HA} \%, X_{2}\right)$ and ribose amount $\left(\mathrm{Rib}, X_{3}\right)$ (Table 1). The filtration time, defined as the time the HA/collagen slurry was filtered before freeze-drying, determines the hydrogel concentration, measured as the difference between the scaffold weight before and after freeze-drying. From preliminary experiments, a low and a high vacuum time, respectively, equal to 0.25 and 5 min of filtration time were selected, thus ensuring a final scaffold concentration of 7.65 wt. $\% \pm 0.86$ wt. $\%$ and 11.28 wt. $\% \pm 2.57$ wt. $\%$, respectively (Figure 1). Hydrogel concentration has been shown to strongly influence scaffold density and hence its morphological, physical and mechanical properties (Drury and Mooney, 2003).

Hydroxyapatite content (wt. \%) levels were set, respectively, at 30 and $70 \%$ compared to the collagen mass fraction. The selected values can be considered as the minimum and maximum theoretical apatite phase contents for the synthesis of hybrid $\mathrm{HA} /$ collagen constructs, with a 70\% HA content typical of subchondral bone and 30-40\% of HA phase typical of tidemark and calcified cartilage (Tampieri et al., 2008).

TABLE 1 | List of experimental input factors (left), with the selected levels (two per each factor, coded as -1 and 1 ) and the output responses, and (right) the $2^{3}$ design matrix with the eight scaffold formulations.

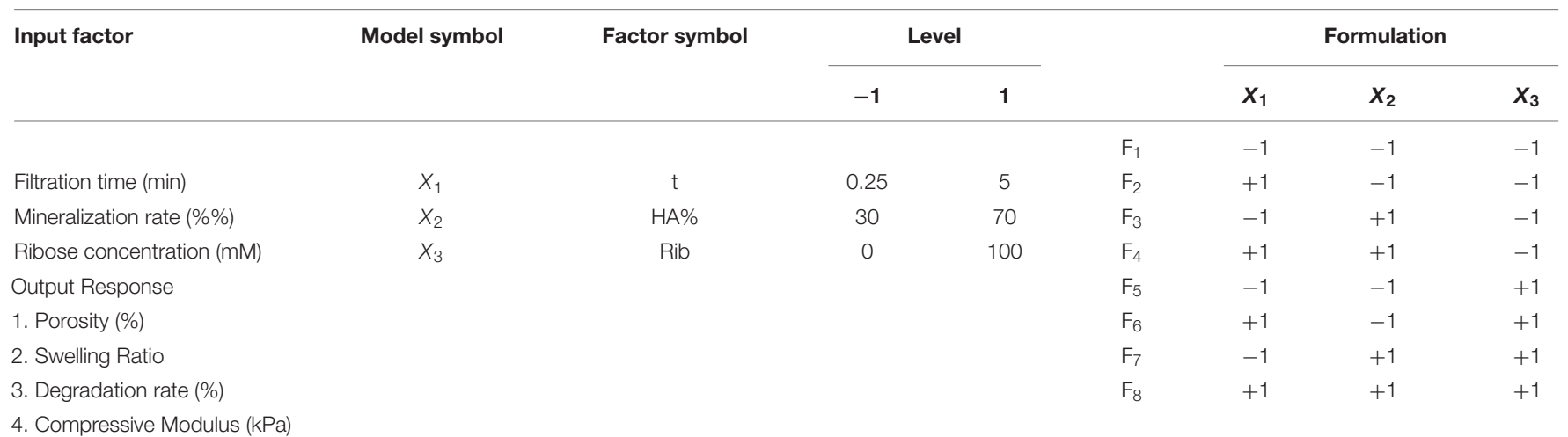

\section{5}
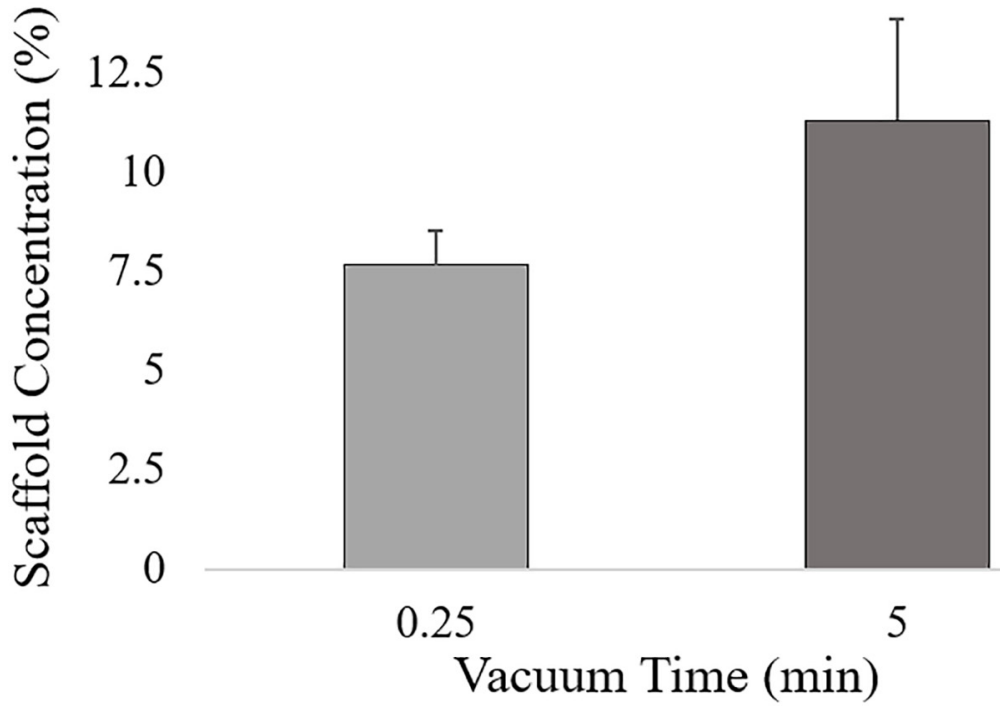

FIGURE 1 | Hydrogel concentration for low (0.25 min) and high (5 min) vacuum time levels, calculated as the ratio between the scaffold weight after freeze-drying and the HA/Collagen wet slurry. 
A

$$
\mathrm{Ca}+\mathrm{Mg} \mathrm{P}+\text { Collagen }
$$

Suspension Suspension
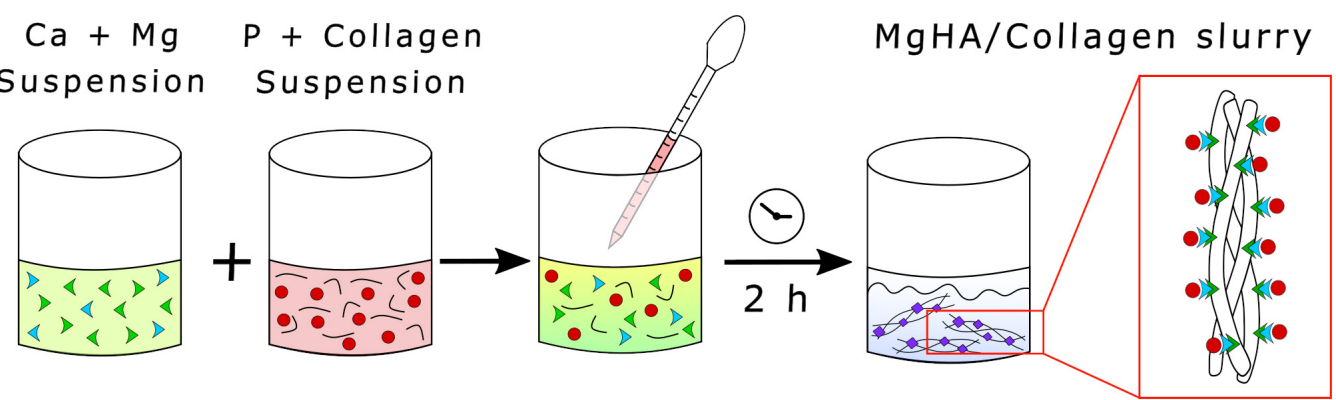

B Only for scaffold F5-F8:

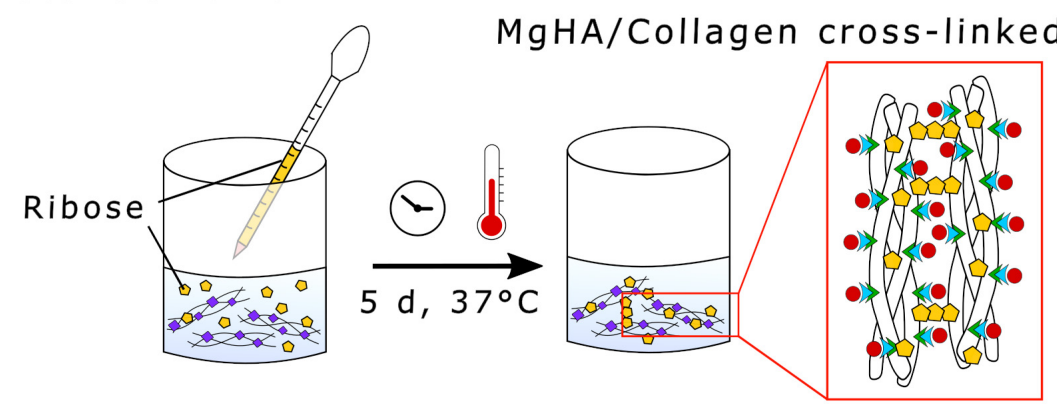

C
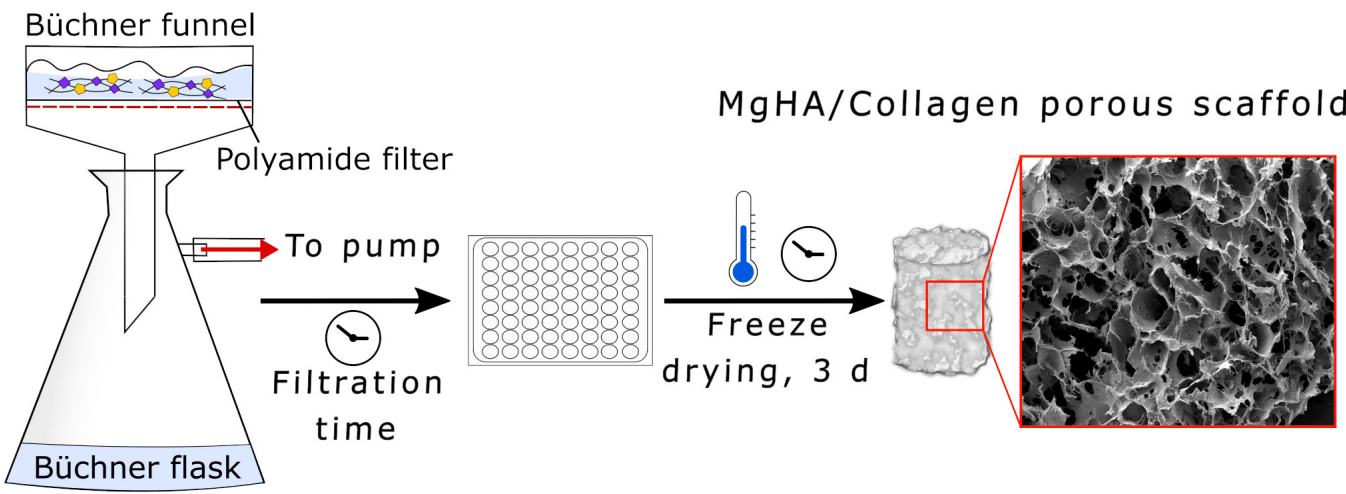

$\left(\right.$ Collagen fibril $>\mathrm{Ca}^{2+}>\mathrm{Mg}^{2+} \bigcirc \mathrm{PO}_{4}{ }^{3-}$

FIGURE 2 | Synthesis of HA/Collagen scaffolds. (A) Collagen biomineralization through neutralization process, (B) MgHA/Collagen slurry glycation with ribose (only for the scaffolds formulations F5-F8), and (C) vacuum filtration and scaffold freeze-drying.

For ribose cross-linking, ribose concentrations up to $250 \mathrm{mM}$ have been tested (Boonkaew et al., 2014) and low concentrations (30 $\mathrm{mM}$ ) have been proven to be effective on intermolecular cross-linking of the collagen fibrils (Chiue et al., 2015; VicensZygmunt et al., 2015; Gostynska et al., 2017). In this work, an intermediate ribose concentration of $100 \mathrm{mM}$ has been selected and the two ribose levels were set, respectively, at 0 (no cross-linking) and $100 \mathrm{mM}$. Other potential processing variables such as freeze-drying conditions and synthesis temperature were kept constant.

The output responses were porosity percentage, swelling ratio, degradation rate at day 30 and compressive modulus as measure of the mechanical behavior (Table 1).

\section{Synthesis of HA/Collagen Scaffolds}

Hybrid HA/collagen scaffolds were prepared through an acid/base reaction (Figure 2). $\mathrm{H}_{3} \mathrm{PO}_{4}$ was dissolved in Milli$\mathrm{Q}$ water and dropped into $100 \mathrm{~g}$ of $1 \mathrm{wt}$. $\%$ collagen to prepare an acidic suspension ( $\mathrm{pH} 2.5)$. A basic suspension $(\mathrm{pH}$ 12.0) was obtained by dispersing $\mathrm{Ca}(\mathrm{OH})_{2}$ in Milli-Q water followed by mechanical stirring, with subsequent addition of $\mathrm{MgCl}_{2} \cdot 6 \mathrm{H}_{2} \mathrm{O}$. The $\mathrm{Ca} / \mathrm{P}(\mathrm{mol})$ ratio was fixed at 1.67 and the $\mathrm{Mg} / \mathrm{Ca}(\mathrm{mol} \%)$ ratio at 5 to achieve a biomimetic $\mathrm{Mg}$-doped HA. The acidic suspension was added to the basic one at room temperature under gentle mechanical stirring, initiating a neutralization process, with a slow decrease of the $\mathrm{pH}$ from 12.0 to 7.5 and simultaneous MgHA nano-crystals nucleation 
onto self-assembling collagen fibers (Figure 2A). After $2 \mathrm{~h}$ of HA maturation at room temperature, the slurry was washed with Milli-Q for two consecutive times with a $150 \mu \mathrm{m}$ sieve to remove the excess of free ions.

Ribose cross-linked scaffolds (Formulations $\mathrm{F}_{5}-\mathrm{F}_{8}$ ) were prepared by adding $2 \mathrm{~g}$ of ribose in a solution of ethanol and PBS (70:30 vol.\%) to obtain a final concentration of $100 \mathrm{mM}$, covering the mineralized slurry and incubating the composite for 5 days at $37^{\circ} \mathrm{C}$ under constant mechanical shaking (Figure 2B). The cross-linked slurry was then filtered twice by a $150 \mu \mathrm{m}$ sieve with Milli-Q to eliminate residues.

A Büchner funnel was inserted into a Büchner flask and connected to a vacuum pump. The slurry was then filtered using a polyamide filter for a filtration time of 0.25 or $5 \mathrm{~min}$ according to the experimental conditions (see Table 1). The gel was distributed in multiwell plates (48-wells format, JET Biofil ${ }^{\circledR}$, China), covered with an $8 \mathrm{~mm}$ diameter polyamide layer and freeze dried (LIO_3000_PLT, 5Pascal, Italy). The process was performed with a controlled freezing temperature slope of $-50^{\circ} \mathrm{C} / \mathrm{h}$ up to $-40^{\circ} \mathrm{C}$ and drying temperature of $2^{\circ} \mathrm{C} / \mathrm{hr}$ from -40 to $20^{\circ} \mathrm{C}$ for $72 \mathrm{~h}$ under constant vacuum of $0.1 \mathrm{mbar}$ (Figure 2C).

\section{Scaffold Characterization Physicochemical Characterization}

Before collecting the data to build the DoE model, the physicochemical properties of the hybrid HA/collagen scaffolds were assessed by Thermogravimetric Analysis (TGA), Inductively Coupled Plasma (ICP), Fourier transform infrared spectroscopy (FTIR) and X-Ray Diffraction (XRD).

The actual amount of inorganic phase was calculated by Thermo Gravimetric Analysis (TGA) (STA 449/C Jupiter, Netzsch, Germany). Briefly, $20 \mathrm{mg}$ of the composite were placed in aluminum crucible and pressed to have full contact with the crucible. The experiment was performed in the temperature range of $30-800^{\circ} \mathrm{C}$ at a heating rate of $10^{\circ} \mathrm{C} / \mathrm{min}$ in air atmosphere. The $\mathrm{HA}$ and collagen mass fractions (wt. \%) were calculated from the TGA curves and then averaged for the formulations with the same $\mathrm{HA} /$ collagen ratio.

The quantitative calculation of $\mathrm{Mg}^{2+}, \mathrm{Ca}^{2+}$, and $\mathrm{PO}_{4}{ }^{3-}$ ions of the mineral phase was assessed by Inductively coupled plasmaoptical emission spectrometry (ICP-OES, Agilent Technologies 5100 ICP-OES, Santa Clara, United States). Briefly, $30 \mathrm{mg}$ of sample were dissolved in $2 \mathrm{ml}$ of nitric acid (65 wt. $\%)$ through sonication for $30 \mathrm{~min}$ and were then diluted in $100 \mathrm{ml}$ of milli-Q water (the experiment was performed in triplicate for each formulation). 422, 279, and $214 \mathrm{~nm}$ were used as wavelengths, respectively, for $\mathrm{Ca}, \mathrm{Mg}$ and $\mathrm{P}$ ions detection.

The chemical interaction between the $\mathrm{Mg}$ doped $\mathrm{HA}$ and the collagen matrix were studied by Fourier Transform Infrared Spectroscopy (FTIR, Nicolet 380, Thermo Fisher Scientific Inc., Waltham, MA, United States). Samples were prepared by mixing $2 \mathrm{mg}$ of scaffold with $200 \mathrm{mg}$ of anhydrous potassium bromide $(\mathrm{KBr})$ as background element and pressed into $7 \mathrm{~mm}$ diameter tablets at 8000 psi. The spectra were acquired in the wavelength range $400-4000 \mathrm{~cm}^{-1}$ at $4 \mathrm{~cm}^{-1}$ resolution.
X-ray diffraction analyses (XRD, D8 Advance, Bruker AXS, Germany) were performed to investigate the scaffolds crystallinity. To clarify the role of the mineralization time, the presence of ribose and $\mathrm{Mg}^{2+}$ ions on samples composition, XRD was performed on scaffolds (i) HA/collagen, $2 \mathrm{~h}$ of mineralization, (ii) HA/collagen, 5 days of mineralization, (iii) MgHA/collagen, 5 days of mineralization and (iv) Ribose cross-linked MgHA/collagen (5 days of mineralization). The diffractometer was equipped with a Lynx-eye position-sensitive detector $(\mathrm{Cu} \mathrm{K} \alpha$ radiation, $\alpha=1.5418 \AA)$. XRD spectra were recorded at a step size $(2 \theta)$ of $0.02^{\circ}$ from $20^{\circ}$ to $80^{\circ}$ and a scan speed of $0.5 \mathrm{~s}$.

\section{Scaffold Porosity}

The theoretical scaffold density $\rho$ was calculated as the ratio between mass $m$ and volume $V$ (cylindrical shape assumption) of the dry scaffold using Equation (1) $(\rho=m / V)$. The effective scaffold density $\rho_{\text {material }}$ was calculated as the sum of the densities of the scaffold components, i.e., apatite, collagen and water phases assumed equal to $3.16 \mathrm{~g} / \mathrm{ml}$ (Haverty et al., 2005), $1.45 \mathrm{~g} / \mathrm{ml}$ (Davidenko et al., 2015) and $1 \mathrm{~g} / \mathrm{ml}$ respectively and multiplied by the weight percentage within the scaffold. The relative density of the scaffolds was obtained by dividing the theoretical density $\rho$ by the $\rho_{\text {material }}$ and the porosity percentage was calculated from the relative density (Karageorgiou and Kaplan, 2005) following Equation (2):

$$
\text { Porosity }(\%)=100 \times\left(1-\rho / \rho_{\text {material }}\right)
$$

\section{Swelling Ratio and Degradation Rate}

The water sorption ability of the scaffolds under physiological conditions was assessed by investigating their swelling behavior. Briefly, cylindrical specimens were weighted in dry conditions and after $24 \mathrm{~h}$ of incubation at $37^{\circ} \mathrm{C}$ in $\mathrm{PBS}$ and the swelling ratio was calculated according to Equation (3): $\left[\left(W_{w}-\right.\right.$ $\left.\left.W_{d}\right) / W_{d}\right]$ (Conshohocken, 2011), where $\mathrm{W}_{\mathrm{w}}$ and $\mathrm{W}_{\mathrm{d}}$ represent the wet and dry weights respectively.

Degradation rate was calculated as the difference between the initial $W_{i}$ and the residual mass $W_{f}$ after 30 days of incubation in PBS solution at $37^{\circ} \mathrm{C}$, as described in Equation (4): [100 $x\left(W_{i}-\right.$ $\left.\left.W_{f}\right) / W_{i}\right]$. Cylindrical scaffolds were immersed in a PBS solution containing $\mathrm{NaN}_{3}$ and maintained under constant shaking; after 30 days of incubation specimens were washed in Milli-Q water and freeze-dried before weighting.

\section{Mechanical Characterization}

Dynamic mechanical analysis (Q800 DMA, TA Instruments, United States) was performed for the compressive strength calculation (Conshohocken, 2011). Cylindrical samples (diameter of $8 \mathrm{~mm}$ and thickness of $10 \mathrm{~mm}$ ) were soaked in PBS for $24 \mathrm{~h}$ before the tests to simulate physiologically wet conditions. Compression tests were performed by setting a ramp force of $0.5 \mathrm{~N} / \mathrm{min}$ up to $5 \mathrm{~N}$ at $37^{\circ} \mathrm{C}$.

\section{Statistical Analysis}

Experimental design and data analysis were performed using Minitab 18 software (Minitab Ltd., United Kingdom). A 2level full factorial design with default generators, number of 
factors equal to 3 and 1 block was selected to build the experimental matrix. Sample size of 80 and 10 replicates for each corner point were chosen to ensure a design power of 0.9, with a level of significance $\alpha$ of 0.05 (Bahçecitapar et al., 2016; Montgomery, 2017). Experiments were performed in randomized order according to the design matrix and data are presented as mean \pm SD. Experimental data from porosity, swelling ratio, degradation rate and compressive modulus were statistically evaluated by general linear model (GLM) analysis of variance (ANOVA) by selecting interactions through third order. The following regression equation was used to evaluate each output (Equation 5):

$$
\begin{aligned}
Y= & b_{0}+b_{1} X_{1}+b_{2} X_{2}+b_{3} X_{3}+b_{12} X_{1} X_{2}+ \\
& b_{13} X_{1} X_{3}+b_{23} X_{2} X_{3}+b_{123} X_{1} X_{2} X_{3}
\end{aligned}
$$

where $Y$ is the measured response, $b_{0}$ represents the intercept, $b_{i, j, k}$ are the linear coefficients, $b_{i j, i k, j k}$ are the estimated coefficients of the two-interaction terms and $b_{i j k}$ is the threeinteraction coefficient. ANOVA results and Pareto charts were evaluated to find the statistical significance of independent variables and interaction terms and eventually reduce the model. Residuals analysis was performed to validate ANOVA assumptions. Main effect, interaction and contour plots were generated to visualize the influence of factors and interactions on the responses.

\section{RESULTS AND DISCUSSION}

\section{Physicochemical Characterization}

Results from TGA showed that the actual HA/collagen ratio for the $70 \% \mathrm{HA}$ theoretical formulations $\left(\mathrm{F}_{3}, \mathrm{~F}_{4}, \mathrm{~F}_{7}, \mathrm{~F}_{8}\right)$ was $50.72 / 49.28$ wt. \%, with a final residual weight comparable to the natural bone composition (Figure 3A; Rana et al., 2017). For the $30 \% \mathrm{HA}$ theoretical formulations $\left(\mathrm{F}_{1}, \mathrm{~F}_{2}, \mathrm{~F}_{5}, \mathrm{~F}_{6}\right)$ the final ratio $\mathrm{HA} /$ collagen was $24.17 / 75.83$ wt. \% (Figure 3B), showing a mineral content that can be compared to the human articular calcified cartilage (Hoemann et al., 2012).

The ICP data (averaged for the formulations HA 70 and $30 \%$, respectively, Table 2) confirmed the presence of $\mathrm{Mg}^{2+}$ ions in the $\mathrm{HA}$ reticulum as well as the nucleation of a calcium deficient low crystalline (1.45-1.60) mineral phase for the 30\% HA scaffold formulations due to $\mathrm{Mg}$ substitution.

FTIR spectra showed the typical HA phosphate group $\left(\mathrm{PO}_{4}{ }^{3-}\right)$ bands at 560-640 and $1030 \mathrm{~cm}^{-1}$ and the collagen type I amide I, II, and III absorption bands (at 1659, 1555, and 1180-1300 $\mathrm{cm}^{-1}$, respectively) (Belbachir et al., 2009), with a broad spectrum typical of a low crystalline composite material (Figure 4). The shift from 1340 to $1337 \mathrm{~cm}^{-1}$ can be attributed to the collagen carboxyl groups stretching due to their interaction with the apatite nanocrystals while the band at $872 \mathrm{~cm}^{-1}$ indicated the carbonation of MgHA nucleated on the collagen fibrils (Minardi et al., 2015). For the ribose cross-linked scaffolds, typical ribose bands corresponding to $\mathrm{C}-\mathrm{O}, \mathrm{C}-\mathrm{C}$ stretching vibrations and the $\mathrm{C}-\mathrm{OH}$ and $\mathrm{C}-\mathrm{C}-\mathrm{O}$ bending vibrations were found in the $1000-1200 \mathrm{~cm}^{-1}$ range (Roy et al., 2010; Huang et al., 2016).

The XRD data showed the presence of the main HA peaks at $25^{\circ}$ and $32^{\circ}$ according to the main lattice reflections of the JCPDS-ICDD file (Card \# 09-0432). The pattern exhibited a scarcely crystalline profile of the mineral phase, with a broad profile, in good agreement with FTIR results, confirming the capability of the adopted biomineralization protocol to closely mimic the natural bone features (Figure 5 and Supplementary Figure S1; Stock, 2015; Ding et al., 2019). The scaffold formulations without ribose $\left(\mathrm{F}_{1}\right.$ to $\left.\mathrm{F}_{4}\right)$ were nucleated for $2 \mathrm{~h}$ before washing and freeze-drying while the formulations containing ribose $\left(\mathrm{F}_{5}\right.$ to $\left.\mathrm{F}_{8}\right)$ were incubated for 5 days to cross-link the collagen. These two different experimental settings determined different $\mathrm{HA}$ maturation time ( $2 \mathrm{~h}$ versus 5 days) (Figures $\mathbf{5 A}, \mathbf{B}$ ), as assessed by the XRD pattern: the formulations containing ribose showed a higher crystallinity due to the longer HA maturation time. XRD analysis was performed also on scaffolds incubated for 5 days w/o magnesium and w/o ribose in order to assess the influence of foreign ions and sugars on the inorganic phase crystallinity. The presence of $\mathrm{Mg}^{2+}$ and ribose contribute in lowering the HA crystallinity but with no significant variation, as previously demonstrated (Supplementary Figure S1; Minardi et al., 2015).

\section{Factorial Design Output Responses}

Average values $(n=10)$ of the porosity percentage, swelling ratio, degradation rate and compressive modulus for each scaffold formulation are shown in Figure 6 and Supplementary Table S1. The variation of the input variables, i.e., filtration time $\left(\mathrm{X}_{1}\right)$, mineralization rate $\left(\mathrm{X}_{2}\right)$ and ribose content $\left(\mathrm{X}_{3}\right)$, resulted in a significant change of the responses. All the scaffold formulations showed a high porosity percentage, from 90 to $96 \%$, which ensures a high surface area suitable for in vitro cells growth, nutrients diffusion and waste removal and fundamental in tissue engineering devices (Freed et al., 1994; Puppi et al., 2010). Water-binding ability, expressed as swelling ratio, varies from $4.18 \pm 0.54$ for $\mathrm{F}_{3}(0.25 \mathrm{~min}, 70 \%$ of $\mathrm{HA}, 0 \mathrm{mM}$ of ribose) to $9.77 \pm 1.11$ for $\mathrm{F}_{5}(0.25 \mathrm{~min}, 30 \%$ HA, $100 \mathrm{mM}$ ), showing minimum values for $70 \% \mathrm{HA}$ noncrossliked scaffolds. Degradation rate, calculated as the weight loss after 30 days of incubation in PBS, ranges from about 7 to $12 \%$ and resulted to be lower for scaffolds with $70 \%$ of apatite content $\left(\mathrm{F}_{3}, \mathrm{~F}_{4}, \mathrm{~F}_{7}\right.$, and $\left.\mathrm{F}_{8}\right)$. The compressive modulus reaches values up to $75 \mathrm{kPa}$ in scaffolds with high level of $\mathrm{HA} \%$ $\left(\mathrm{F}_{3}\right.$ and $\left.\mathrm{F}_{4}\right)$.

\section{Data Analysis From Factorial Design}

Data from ANOVA and Pareto charts (Supplementary Table S2 and Supplementary Figure S2) were used to identify the significant factors and to find the regression coefficients based on p-value evaluation. The non-significant terms ( $p$-value $<\alpha$, with level of significance $\alpha$ of 0.05 ) could be deleted and the model reduced just for the degradation rate, in which the interaction terms resulted to be non statistically significant. For the other 
A

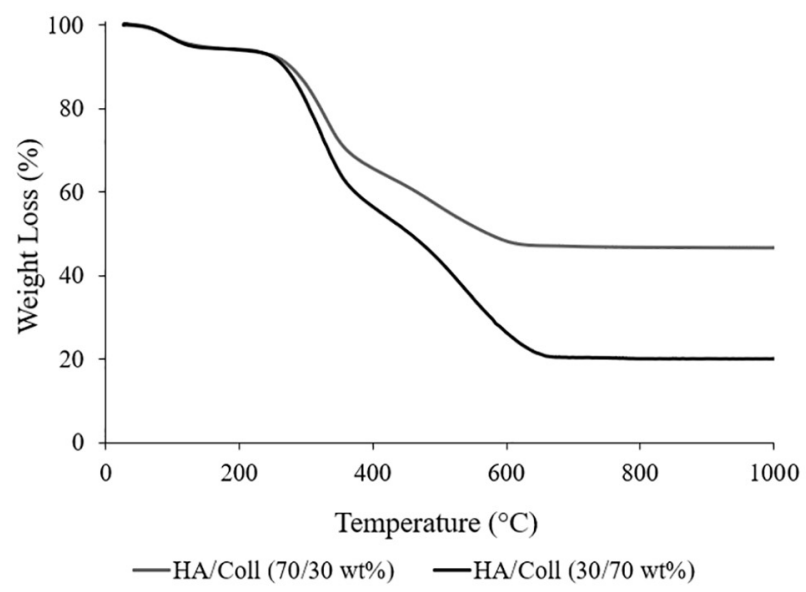

B

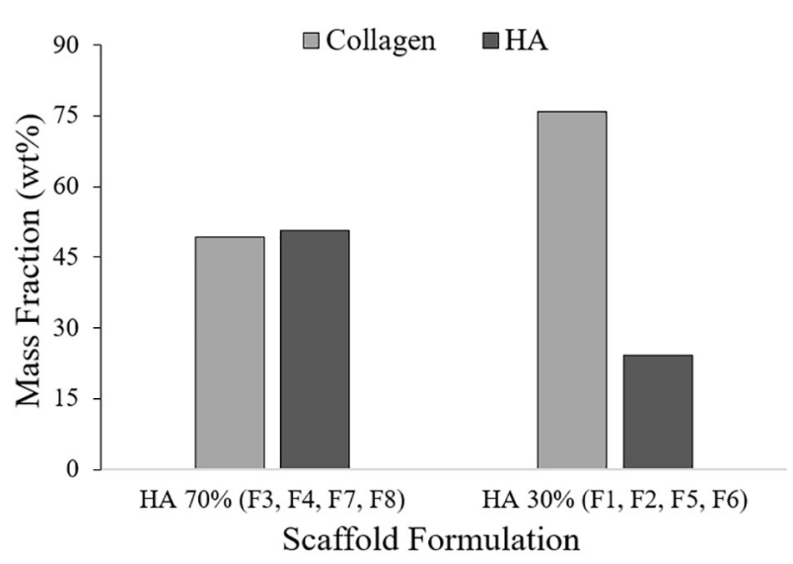

FIGURE 3 | (A) Representative TGA curves of the formulations HA/collagen 70/30 wt. \% and 30/70 wt. \% (F1 and F7) and (B) average data of the HA and collagen mass fractions (wt. \%).

outputs, the non significant terms were included to respect the model hierarchy, leading to the following regression equations:

$$
\begin{aligned}
& \text { Por }=97.10-1.36 X_{1}-0.089 X_{2}-0.04 X_{3}+0.023 X_{1} X_{2}+ \\
& 0.012 X_{1} X_{3}+0.0013 X_{2} X_{3}-0.00027 X_{1} X_{2} X_{3} \\
& S w=10.72-0.84 X_{1}-0.094 X_{2}-0.008 X_{3}+0.013 X_{1} X_{2}+ \\
& 0.0069 X_{1} X_{3}+0.00092 X_{2} X_{3}-0.0002 X_{1} X_{2} X_{3} \\
& \text { Degr }=16.24-0.108 \mathrm{X}_{2}-0.011 \mathrm{X}_{3}(\text { ReducedModel }) \\
& \begin{array}{c}
E=-28.17-1.38 X_{1}+1.24 X_{2}+0.4 X_{3}+0.067 X_{1} X_{2}+ \\
0.036 X_{1} X_{3}+-0.012 X_{2} X_{3}-0.001 X_{1} X_{2} X_{3}
\end{array}
\end{aligned}
$$

The analysis of residual plots was carried out for each output: the normal probability plots and the histograms of residuals confirmed a normal distribution of data with no skewness and few outliers for porosity, swelling ratio and degradation rate (Supplementary Figure S3). The normal probability plot for compressive modulus showed a p-value lower than $\alpha$ and a curved distribution, violating the assumption of normal distribution and indicating that a second order term needs probably to be included in the model. However, considering the results from ANOVA analysis, the model was considered

TABLE 2 | ICP average values for the formulations HA 70\% and HA 30\%.

\begin{tabular}{lccc}
\hline Formulation & Ca/P (mol) & Mg/Ca (mol\%) & (Ca+Mg)/P (mol) \\
\hline HA 70\% (F3, F4, F7, F8) & $1.74 \pm 0.028$ & $3.62 \pm 0.45$ & $1.80 \pm 0.034$ \\
HA 30\% (F1, F2, F5, F6) & $1.44 \pm 0.028$ & $1.38 \pm 0.096$ & $1.46 \pm 0.029$
\end{tabular}

sufficiently adequate to describe the dataset. High values of the coefficient of determination $R^{2}$, adjusted $R^{2}\left(R_{\text {adj }}^{2}\right)$ and predicted $R^{2}$ ( $R_{\text {Pred }}^{2}$ ) (close to 1 ) were obtained for all the outputs, indicating a good fit of the response equations with the experimental data and showing a good predictive capability of the model (Supplementary Table S2). The "Residuals versus fits" and "Residual versus order" graphs confirmed the random data distribution and the residuals independency for all the responses.

Interaction and contour plots of porosity, swelling and compressive modulus were evaluated to investigate the influence of factor interactions on scaffold performances. The main effect plots of degradation have been studied since there was no evidence of interaction among factors for this response. The main effect plots for the other responses are shown in Supplementary Figure S4.

\section{Porosity}

The input variables $\mathrm{X}_{1}$ and $\mathrm{X}_{3}$ had the largest effect (Equation 6 and Supplementary Figure S2A), meaning they are the most influencing parameters in determining the scaffold porosity (Supplementary Figure S4). However, basing on the ANOVA results, the interactions $\mathrm{t}^{*} \mathrm{HA} \%$ and $\mathrm{HA} \%{ }^{*} \mathrm{Rib}$ resulted to be statistically significant, thus the interaction effects needed to be interpreted since the main effects per se can be misleading. The interaction plot (Figure 7A) reports the mean of porosity values as function of the combination of the three input variables $\mathrm{X}_{1}, \mathrm{X}_{2}$ and $\mathrm{X}_{3}$. The lack of parallelism indicates that, when tuning one of the three factors, the output variation is dependent on the other factors (Montgomery and Runger, 2003).

Although the HA\% resulted to be not statistically significant, as shown in the main effects plot (Supplementary Figure S4A), the interaction effect between porosity and filtration time is dependent on the mineral phase content. The $t^{*} \mathrm{HA} \%$ graph shows that shorter filtration times leads to higher porosity, 


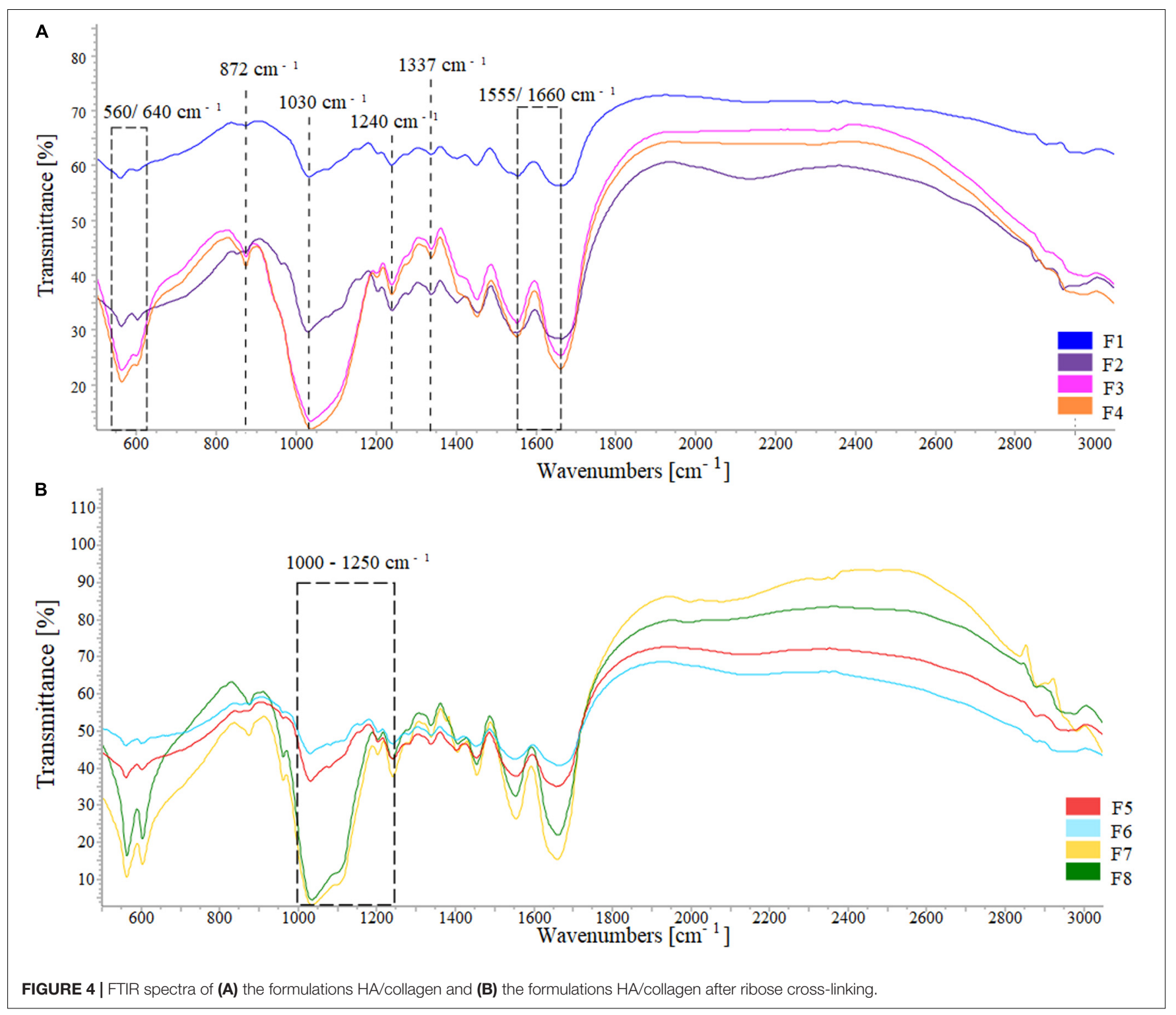

with similar values for both the HA\% level tested. A filtration time of $5 \mathrm{~min}$ decreases significantly the porosity in $30 \%$ HA scaffolds while the output remains almost constant for $70 \%$ HA formulations. As previously shown, scaffold porosity is inversely proportional to stiffness (Sudarmadji et al., 2011) so porosity in $70 \%$ HA formulation can be expected to be lower for any input parameter tested. However, the results from both the main and interaction effects show a high impact of the filtration time on the final porosity, with 5 min filtration time inducing a drastic porosity decrease for $30 \%$ HA content. The behavior can be attributed to the capability of the constructs to be further compressed when the HA\% is lower. A high vacuum time thus eliminates more water in $30 \%$ HA slurries, leading to higher scaffold concentrations and consequently to lower porosity percentage (Figure 1) while in $70 \% \mathrm{HA}$ scaffolds formulation the porosity remains almost constant for both the filtration time tested because of the high mineral phase content, that reduces the scaffold compressibility. The input values $t$ of $0.25 \mathrm{~min}$ and $\mathrm{HA} 30 \%$ resulted in the highest scaffold porosity.

The HA\%*Rib graph showed that the presence of ribose is responsible for higher porosity percentages for both the HA\% tested. While a small difference of the output is noticed in 30\% HA formulations, either cross-linked or not, in $70 \%$ HA scaffolds the ribose substantially contributes in increasing the porosity compared to non cross-linked matrices. The trend can be related to the porogen effect of ribose, that increases both the pore size and porosity degree, as previously reported (Karageorgiou and Kaplan, 2005) and is confirmed by the $\mathrm{X}_{3}$ main effect plot (Supplementary Figure S4A). In absence of ribose, $70 \%$ HA scaffolds resulted less porous than $30 \% \mathrm{HA}$, probably due to the higher mineral content, as discussed above. 
A

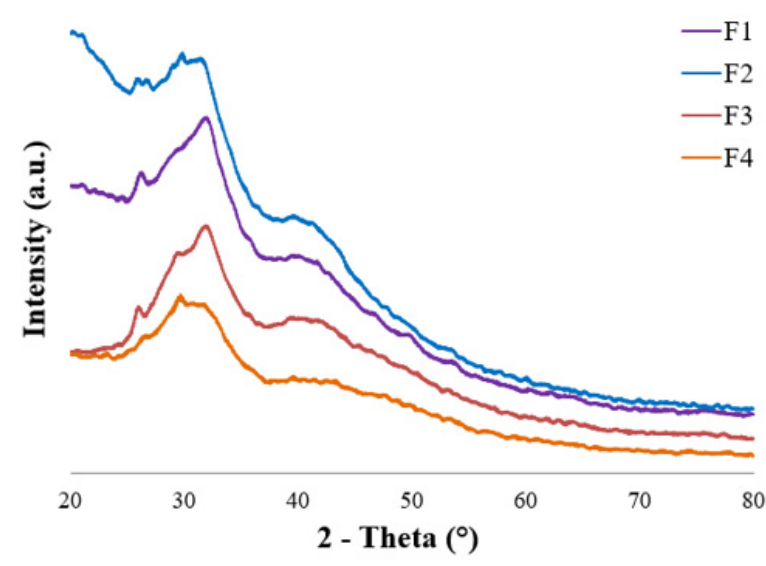

B

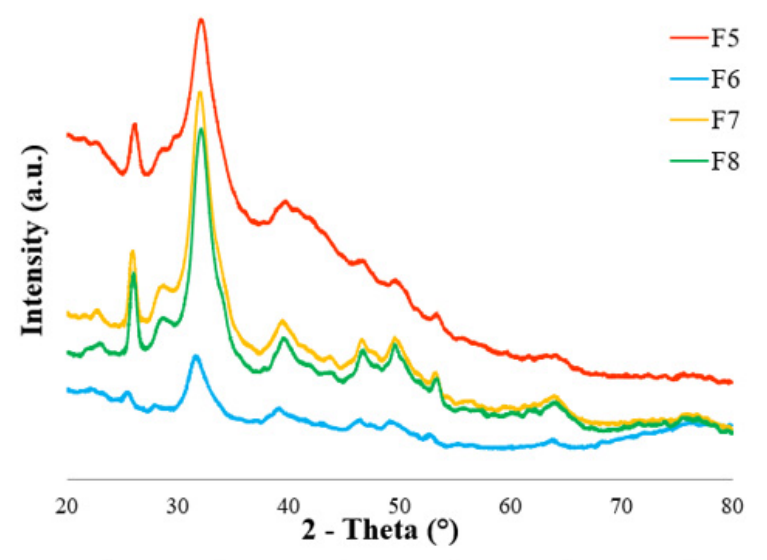

FIGURE 5 | XRD patterns of (A) formulations F1-F4 (2 h of HA maturation time, no ribose cross-linking) and (B) formulations F5-F8 (5 days of HA maturation time, ribose cross-linking).

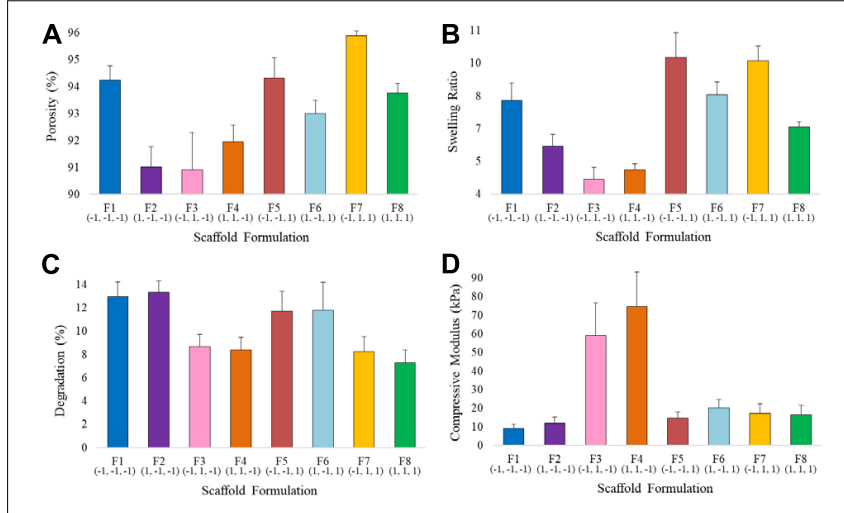

FIGURE 6 | Average values of (A) Porosity, (B) Swelling Ratio, (C) Degradation Rate, and (D) Compressive Modulus for the eight scaffold formulations.

\section{Swelling Ratio}

The swelling ratio equation showed that all the interaction terms are statistically significant. Both the plots $\mathrm{t}^{*} \mathrm{Rib}$ and HA\%* Rib showed that the effect of Rib on swelling is greater for $100 \mathrm{mM}$ compared to $0 \mathrm{mM}$. For the $\mathrm{t}^{*} \mathrm{HA} \%$, the $30 \% \mathrm{HA}$ content determines higher swelling in comparison to higher $\mathrm{HA}$ /collagen ratio (Figure $\mathbf{7 B}$ ).

The $\mathrm{X}_{1} \mathrm{X}_{3}$ interaction shows that, for a slurry filtered with low filtration time, the presence of ribose plays a key role in determining higher swelling ratio compared to non cross-linked scaffolds. For prolonged filtration time, the swelling ratio resulted to be reduced, with little effect of ribose. However, the highest decrease is noticed in cross-linked scaffolds due to an increased collagen stability at higher hydrogel concentration (Hiremath and Vishalakshi, 2012).

Conversely, the effect of ribose on swelling resulted reversed when the influence of $\mathrm{HA} \%$ is considered $\left(\mathrm{X}_{2} \mathrm{X}_{3}\right.$ interaction): ribose has a large effect on average swelling in 70\% scaffolds (formulations $\mathrm{F}_{3}$ and $\mathrm{F}_{4}$ ), showing that the absence of crosslinking leads to a drastic reduction of water binding capability. In contrast to the majority of the cross-linking agents, that reduce the collagen swelling capability (Reháková et al., 1996; Charulatha and Rajaram, 2003), the bonding between the aldehyde groups of ribose with the amino groups of collagen during cross-linking influences the swelling positively (Roy et al., 2010; Krishnakumar et al., 2017). The effect is more pronounced for 30\% HA scaffolds due to the higher collagen availability and can be related to the porogen action that the ribose exerts, leading to an increased water uptake capability compared to non cross-linked matrices (Figure 7A). Thus, the use of non-enzymatic glycation ensures the fabrication of stiffer collagenic scaffolds while ensuring high surface/volume ratios, able to promote cells adhesion and matrix colonization (Gostynska et al., 2017; Krishnakumar et al., 2018). The analysis of $\mathrm{X}_{1} \mathrm{X}_{2}$ interaction showed that the HA\% content has a higher effect on swelling for low filtration time and the maximum swelling ration is obtained for 30\% HA scaffolds filtered for $0.25 \mathrm{~min}$.

\section{Degradation Rate}

The regression equation of degradation rate revealed the statistical significance of the two main effects HA\% and ribose while no significant interaction effects were found for the analyzed dataset (Supplementary Figure S2). These results enabled the model to be reduced, thus the interaction terms and the variable $\mathrm{X}_{1}$ could be eliminated in order to have more precise predictions, as condirmed by the values of $R^{2}$ adj and $R^{2}$ peed of the reduced model (Supplementary Table S2). Figure 7C shows the main effect plot for the relevant input factors, with each graph reporting the mean response for the two levels studied. The average degradation resulted to be 12.47 and $8.16 \%$ for 30 and $70 \%$ HA scaffold formulations, respectively. In fact, a higher mineral content content has been shown to affect the degradation 

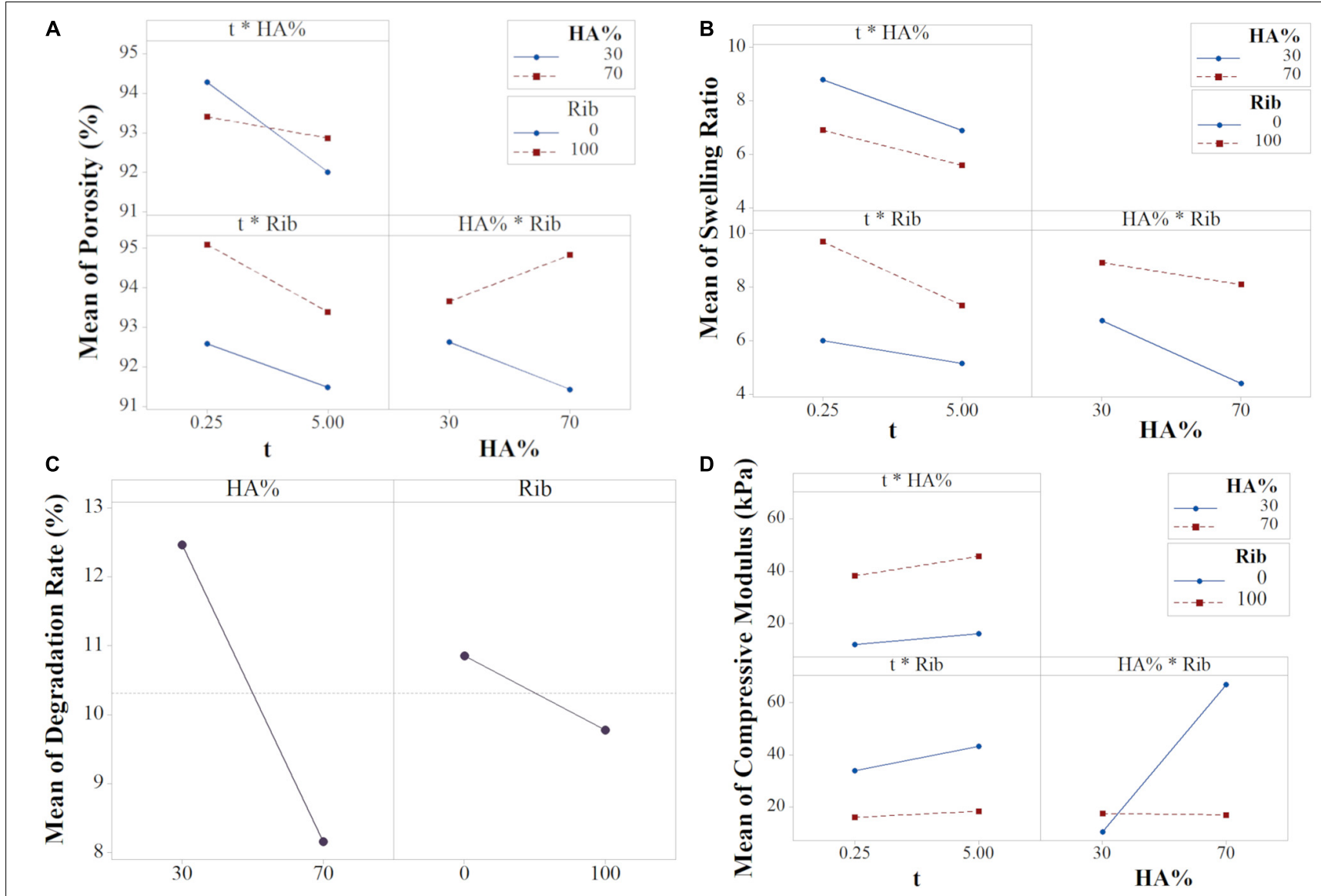

FIGURE 7 | Interaction plots for (A) Porosity, (B) Swelling Ratio, (D) Compressive Modulus, and (C) Main plot for Degradation (data from the reduced model).

degree of the polymeric phase by stabilizing the scaffold structure, a mechanism that results of great interest for in vivo applications, when the scaffold degradation kinetics needs to be properly tuned to match the tissue regeneration timing (Navarro et al., 2006; Rezwan et al., 2006; Tampieri et al., 2008).

With a similar trend, the presence of cross-linker reduced the mean degradation rate from 10.85 to $9.78 \%$ in comparison to non-crosslinked scaffolds. Ribose is responsible for collagen glycation through a protein-to-protein crosslinking mechanism, that leads to a reduced scaffold solubility (Krishnakumar et al., 2017).

\section{Mechanical Properties}

The compressive modulus equation showed that the $\mathrm{X}_{2} \mathrm{X}_{3}$ interaction is statistically significant. The HA\%* Rib interaction plot shows that in the $30 \% \mathrm{HA}$ formulation the effect of ribose is lower compared to the $70 \% \mathrm{HA}$, however it can be noticed that the glycation process with a ribose concentration of $100 \mathrm{mM}$ increases the modulus of about 1.6-fold $\left(\mathrm{F}_{2}\right.$ and $\mathrm{F}_{6}$ compared to $\mathrm{F}_{1}$ and $\mathrm{F}_{5}$ respectively). 1 wt. $\%$ collagen gels have been reported to have an elastic modulus of $4 \mathrm{kPa}$ and ribose at concentration of $250 \mathrm{mM}$ is responsible for increasing their stiffness up to 10 times (Sheu et al., 2001; Roy et al., 2010; Mason et al., 2013). In our study, the effect of the ribose on collagen stiffness is lower compared to literature data since the efficiency of the glycation reaction can be hampered by the presence of the mineral phase, that reduces the availability of collagen free sites. Still, the modulus resulted to be higher in 30\% HA cross-linked scaffolds compared to absence of glycation. The prevailing interaction of HA\% with the collagen fibrils during the biomineralization process is further confirmed in $70 \% \mathrm{HA}$ formulation, for whom the modulus remained almost constant in cross-linked devices $\left(\mathrm{F}_{5}-\mathrm{F}_{8}\right)$ while the specimens with non cross-linked collagen matrix resulted to be almost four times stiffer (average compressive modulus higher than $70 \mathrm{kPa}$ ), as confirmed by the main effects plot (formulations $\mathrm{F}_{3}$ and $\mathrm{F}_{4}$, Figures $6 \mathrm{D}$, 7D and Supplementary Figure S3C). The result can be related to the HA nucleation process: in scaffolds with $70 \%$ $\mathrm{HA}$, collagen shows a reduced number of free sites for the ribose bond since it is already linked to apatite nano-crystals. This condition determines heterogeneities and reduction of the cross-linking (Anseth et al., 1996), thus inducing a nonsignificant increase of mechanical strength in $70 \%$ HA crosslinked scaffolds.

Collagen cross-linking has shown to affect both the compressive modulus and the swelling in 30\% HA matrices, producing an effect that can be compared to the function of 
proteoglycans (PGs) in the deep zone of the cartilage site. In fact, the negative charge of PGs determines the tissue swelling pressure, making these molecules acting as cartilage bio-bearings (Hussainova and Ghaemi, 2008; Dëdinaitë, 2012; Jahn et al., 2016; Armiento et al., 2018). Ribose crosslinking has shown to induce higher fluid uptake properties in 30\% HA devices: the cross-linking caused an increase of the average swelling from 6.75 to $8.92 \%$ compared to non-cross-linked scaffolds $\left(\mathrm{F}_{5}, \mathrm{~F}_{6}\right.$ versus $\left.\mathrm{F}_{1}, \mathrm{~F}_{2}\right)$ (Responte et al., 2007; Roy et al., 2008). In a similar fashion, the stiffness of the matrices increases from $10.55 \mathrm{kPa}$ to 17.48 $\mathrm{kPa}$, making the glycation process a valid approach for mimicking the articular cartilage matrix behavior in vivo (Gostynska et al., 2017).

$2 \mathrm{D}$ contour maps helped in further elucidating the input/output relationship and have been plotted as function of $\mathrm{X}_{2}$ and $\mathrm{X}_{3}$ (vacuum time $\mathrm{X}_{1}$ was maintained at a fix level). In order to show the optimum of each response, porosity and swelling have been plotted by keeping the filtration time $t=0.25 \mathrm{~min}$ while the high level ( $t=5 \mathrm{~min}$ ) has been selected for degradation and compressive modulus (Figure 8). The lack of parallelism in isporesponse lines indicated the presence of relevant interactions (Leardi, 2009), except for the degradation rate, in agreement with the model equation (Supplementary Figure S5). High levels of both $\mathrm{HA} \%$ and ribose ensure the maximum porosity rate (>95\%, Figure 8A). Swelling behavior increased for cross-linked scaffolds while resulted to be minimum for high HA\% level in non cross-linked devices. As confirmed by interaction plots, the $70 \% \mathrm{HA}$ formulation provided the maximum compressive modulus $(>70 \mathrm{kPa})$ in absence of ribose.

\section{Response Optimization for the Design of Osteochondral Multi-Layer Scaffolds}

Starting from the DoE model built on our experimental data, response optimization was performed to set the ideal input parameters for the synthesis of multi-layer scaffolds with graded HA content that can mimic the osteochondral site.

Constructs for clinical application should provide suitable mechanical support to the injured area as well as degradation kinetics comparable to the tissue regeneration (Hutmacher, 2000; Pivonka and Dunstan, 2012). Therefore, in the optimization process, the mimicry of the subchondral bone was ensured by maximizing the compressive modulus while minimizing the degradation rate and the porosity percentage. Since the degradation kinetics is accelerated in vivo compared to in vitro studies (Lam et al., 2009), a minimum degradation rate was chosen during the optimization. A minimization of the porosity was selected because the subcondral bone is corticalized, showing a reduced porosity compared to the adjacent tissues (Burr, 2004). However, a porosity percentage exceeding 90\% was secured, as required by tissue engineering criteria (Puppi et al., 2010). Maximum swelling ratio and porosity percentage, with a constrained $\mathrm{HA} \%$ value ranging from 30 to $40 \%$ were chosen as optimal input variables for the calcified cartilage region.
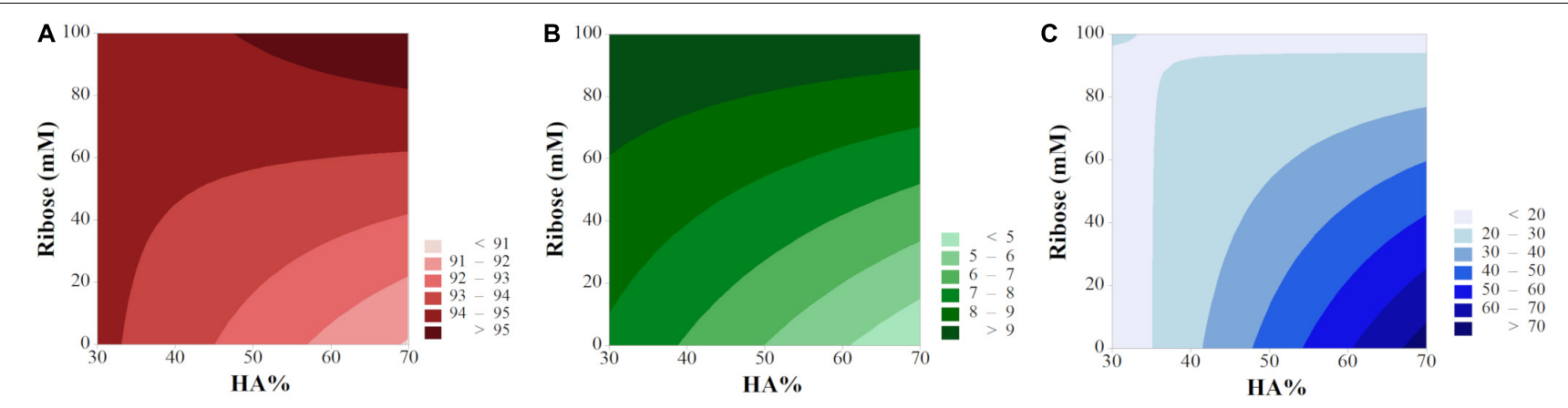

FIGURE 8 | Contour plots for (A) Porosity, (B) Swelling Ratio, and (C) Compressive Modulus.

TABLE 3 | Optimization values and simulation solutions (estimated input, output fit and statistical intervals) for subchondral bone and calcified cartilage, where $\downarrow=$ min, $\uparrow=\max , \mathrm{D}=$ Composite Desirability $(0-1), \mathrm{Cl}=$ Confidence Interval, $\mathrm{Pl}=$ Prediction Interval.

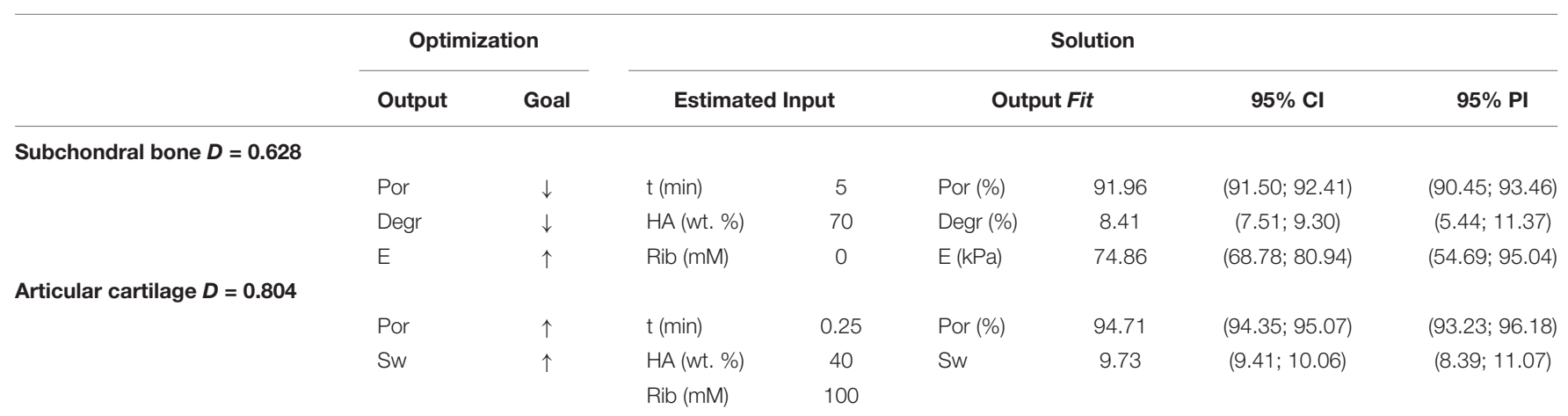


Results from the simulation showed that calcified cartilage can be mimicked in this experimental setup by using low level of filtration time, $40 \%$ of $\mathrm{HA}$ content and a ribose concentration of $100 \mathrm{mM}$ while the $\mathrm{F}_{4}$ formulation represents the optimal solution to mimic subchondral bone ( $5 \mathrm{~min}$ of vacuum time, $70 \%$ $\mathrm{HA}$ and no ribose) (Table 3 ). Composite desirability (D) values revealed a good optimization of the whole set of responses for both cartilage $(D=0.8)$ and bone $(D=0.63)$. Furthermore, low values of Standard Error Fit (SE Fit) and narrow ranges of 95\% confidence interval (CI) and prediction interval (PI) indicate a precise estimate of the mean responses and prediction accuracy.

\section{CONCLUSION}

In this work, experimental design (DoE) was used to investigate the role and interaction of critical process parameters on hybrid $\mathrm{HA} /$ collagen scaffold performances. A $2^{3}$ factorial design was chosen to study the role of hydrogel concentration (modulated by varying the filtration time), hydroxyapatite content and ribose glycation on mineralized constructs in order to build a model for the fabrication of multilayer scaffolds for osteochondral regeneration. The physicochemical analyses confirmed the nucleation of a poorly crystalline $\mathrm{HA}$ mineral phase, the incorporation of $\mathrm{Mg}^{2+}$ ions in the $\mathrm{HA}$ lattice and ribose glycation for cross-linked scaffolds. XRD data confirmed that HA crystallinity is always low due to its growth in close interaction with collagen and mainly affected by the maturation time. Data collected for scaffold porosity, swelling, degradation rate and compressive modulus were investigated as outputs and the values obtained from the ANOVA confirmed a good predictability of the mathematical models.

Results revealed that the degradation rate was negatively affected by high levels of HA\% and ribose as individual factors since a higher mineralization degree, as in sample $70 \% \mathrm{HA}$, and cross-linking are responsible to stabilize the scaffold structure. The combined use of low filtration time and low HA\% produced scaffolds showing the maximum degree of porosity and swelling while the interaction between $\mathrm{HA} \%$ and ribose resulted to be the most significant factor in determining the scaffolds porosity, swelling and mechanical behavior. Particularly, the glycation of collagen led to an increase of both porosity and swelling degrees, showing that ribose acts on collagen matrices as a porogen agent and augments the water uptake capability. The effect of ribose on stabilizing the collagen structure was also observed in 30\% HA cross-linked formulations, that showed an increased compressive modulus. The results confirmed the advantage of using non-enzymatic glycation of collagen matrices as non-toxic

\section{REFERENCES}

Anseth, K. S., Bowman, C. N., and Brannon-Peppas, L. (1996). Mechanical properties of hydrogels and their experimental determination. Biomaterials 17 , 1647-1657. doi: 10.1016/0142-9612(96)87644-7

Armiento, A. R., Stoddart, M. J., Alini, M., and Eglin, D. (2018). Biomaterials for articular cartilage tissue engineering: learning from biology. Acta Biomater. 65, 1-20. doi: 10.1016/j.actbio.2017.11.021 and biocompatible method to obtain highly porous scaffolds with enhanced mechanical stability. Furthermore, ribose glycation caused a response comparable to that of cartilage proteoglycans in the mineralized cartilage, thus ensuring a proper swelling pressure for resisting compressive loads.

The model was then used to optimize the input variables for the synthesis of osteochondral devices: results showed that the ideal input parameters to fabricate calcified cartilage and subchondral bone could be designed in a fast and easy way from the DoE model and the experimental data previously collected.

This study demonstrated that factorial design is an effective statistical method for analyzing, optimizing and standardizing complex biomimetic processes and more sophisticated DoE models for the analysis of the whole osteochondral region, including non-mineralized cartilage, are currently under investigation. We have previously demonstrated the cytocompatibility of our constructs for cartilage and bone regeneration (Gostynska et al., 2017; Krishnakumar et al., 2017) and further biological evaluation will be pursued in future studies.

\section{DATA AVAILABILITY STATEMENT}

All datasets presented in this study are included in the article/Supplementary Material.

\section{AUTHOR CONTRIBUTIONS}

$\mathrm{AD}, \mathrm{EC}$, and MS conceived the presented study. AD carried out the experiment with support from EC and MS in the planning and analysis of data. MS and AT supervised the project. AD wrote the manuscript with input from all authors. All authors contributed to the article and approved the submitted version.

\section{FUNDING}

This work was supported by the regional fundings from NanoCoatings project (POR-FESR 2014-2020, Grant No. D32I16000040009) as well as by the National Research Council of Italy (ISTEC-CNR).

\section{SUPPLEMENTARY MATERIAL}

The Supplementary Material for this article can be found online at: https://www.frontiersin.org/articles/10.3389/fbioe. 2020.00743/full\#supplementary-material

Bahçecitapar, M., Karadağ Ataş, Ö., and Aktaş Altunay, S. (2016). Estimation of sample size and power for general full factorial designs. Ýstatistikçiler Derg. Ýstatistik Aktüerya 9, 79-86.

Belbachir, K., Noreen, R., Gouspillou, G., and Petibois, C. (2009). Collagen types analysis and differentiation by FTIR spectroscopy. Anal. Bioanal. Chem. 395, 829-837. doi: 10.1007/s00216-009-3019-y

Bhattacharjee, M., Coburn, J., Centola, M., Murab, S., Barbero, A., Kaplan, D. L., et al. (2015). Tissue engineering strategies to study cartilage development, 
degeneration and regeneration. Adv. Drug Deliv. Rev. 84, 107-122. doi: 10.1016/ j.addr.2014.08.010

Bittner, S. M., Smith, B. T., Diaz-Gomez, L., Hudgins, C. D., Melchiorri, A. J., Scott, D. W., et al. (2019). Fabrication and mechanical characterization of 3D printed vertical uniform and gradient scaffolds for bone and osteochondral tissue engineering. Acta Biomater. 90, 37-48. doi: 10.1016/j.actbio.2019. 03.041

Boonkaew, B., Tompkins, K., Manokawinchoke, J., Pavasant, P., and Supaphol, P. (2014). Characterization and cytological effects of a novel glycated gelatine substrate. Biomed. Mater. 9:025001. doi: 10.1088/1748-6041/9/2/025001

Brodsky, B., Berg, R. A., Avigad, G., Eikenberry, E., Jain, M., and Tanaka, S. (1990). Collagen-based matrices ribose cross-linked. U.S. Patent No 4971954. Washington, DC: U.S. Patent and Trademark Office.

Burr, D. B. (2004). Anatomy and physiology of the mineralized tissues: role in the pathogenesis of osteoarthrosis. Osteoarthr. Cartil. 12, 20-30. doi: 10.1016/j.joca. 2003.09.016

Castro, N. J., O'Brien, J., and Zhang, L. G. (2015). Integrating biologically inspired nanomaterials and table-top stereolithography for 3D printed biomimetic osteochondral scaffolds. Nanoscale 7, 14010-14022. doi: 10.1039/c5nr03425f

Charulatha, V., and Rajaram, A. (2003). Influence of different crosslinking treatments on the physical properties of collagen membranes. Biomaterials 24, 759-767. doi: 10.1016/S0142-9612(02)00412-X

Chen, W., Tian, X., He, W., Li, J., Feng, Y., and Pan, G. (2020). Emerging functional materials based on chemically designed molecular recognition. BMC Mater. 2:1. doi: 10.1186/s42833-019-0007-1

Chiue, H., Yamazoye, T., and Matsumura, S. (2015). Localization of the dominant non-enzymatic intermolecular cross-linking sites on fibrous collagen. Biochem. Biophys. Res. Commun. 461, 445-449. doi: 10.1016/j.bbrc.2015.04.011

Conshohocken, W. (2011). Standard test method for compressive properties of rigid plastics 1. Annu. B. ASTM Stand. 08, 1-7. doi: 10.1520/D0695-10.2

Davidenko, N., Schuster, C. F., Bax, D. V., Raynal, N., Farndale, R. W., Best, S. M., et al. (2015). Control of crosslinking for tailoring collagen-based scaffolds stability and mechanics. Acta Biomater. 25, 131-142. doi: 10.1016/j.actbio.2015. 07.034

Dean, A., Daniel, V., and Danel, D. (2017). Design and Analysis of Experiments. Berlin: Springer. doi: 10.1007/978-3-319-52250-0

Dëdinaitë, A. (2012). Biomimetic lubrication. Soft Matter. 8, 273-284. doi: 10.1039/ C1SM06335A

Ding, M., Koroma, K. E., Sorensen, J. R., Sandri, M., Tampieri, A., Jespersen, S. M., et al. (2019). Collagen-hydroxyapatite composite substitute and bone marrow nuclear cells on posterolateral spine fusion in sheep. J. Biomater. Appl. 34, 365-374. doi: 10.1177/0885328219851315

Drury, J. L., and Mooney, D. J. (2003). Hydrogels for tissue engineering: scaffold design variables and applications. Biomaterials 24, 4337-4351. doi: 10.1016/ S0142-9612(03)00340-5

Eleswarapu, S. V., Chen, J. A., and Athanasiou, K. A. (2011). Temporal assessment of ribose treatment on self-assembled articular cartilage constructs. Biochem. Biophys. Res. Commun. 414, 431-436. doi: 10.1016/j.bbrc.2011. 09.107

Freed, L. E., Vunjak-Novakovic, G., Biron, R. J., Eagles, D. B., Lesnoy, D. C., Barlow, S. K., et al. (1994). Biodegradable polymer scaffolds for tissue engineering. Biotechnology 12, 689-693. doi: 10.1038/nbt0794-689

Giorgi, P., Capitani, D., Sprio, S., Sandri, M., Tampieri, A., Canella, V., et al. (2017). A new bioinspired collagen-hydroxyapatite bone graft substitute in adult scoliosis surgery: results at 3-year follow-up. J. Appl. Biomater. Funct. Mater. 15, e262-e270. doi: 10.5301/jabfm.5000366

Gostynska, N., Krishnakumar, G. S., Campodoni, E., Panseri, S., Montesi, M., Sprio, S., et al. (2017). 3D porous collagen scaffolds reinforced by glycation with ribose for tissue engineering application. Biomed. Mater. 12:055002. doi: 10.1088/1748-605X/AA7694

Haverty, D., Tofail, S. A. M., Stanton, K. T., and McMonagle, J. B. (2005). Structure and stability of hydroxyapatite: density functional calculation and Rietveld analysis. Phys. Rev. B 71:094103. doi: 10.1103/PhysRevB.71.094103

Hiremath, J. N., and Vishalakshi, B. (2012). Effect of Crosslinking on swelling behaviour of IPN hydrogels of Guar Gum and Polyacrylamide. Der Pharma Chem. 4, 946-955.
Hoemann, C. D., Lafantaisie-Favreau, C. H., Lascau-Coman, V., Chen, G., and Guzmán-Morales, J. (2012). The cartilage-bone interface. J. Knee Surg. 25, 85-97. doi: 10.1055/s-0032-1319782

Holzapfel, B. M., Reichert, J. C., Schantz, J. T., Gbureck, U., Rackwitz, L., Nöth, U., et al. (2013). How smart do biomaterials need to be? A translational science and clinical point of view. Adv. Drug Deliv. Rev. 65, 581-603. doi: 10.1016/j.addr. 2012.07.009

Huang, Y. T., Liao, H. F., Wang, S. L., and Lin, S. Y. (2016). Glycation and secondary conformational changes of human serum albumin: study of the FTIR spectroscopic curve-fitting technique. AIMS Biophys. 3, 247-260. doi: 10.3934/ biophy.2016.2.247

Hussainova, I., and Ghaemi, H. (2008). Biobearings: where mechanics meets biology. Proc. Est. Acad. Sci. 57, 232-240.

Hutmacher, D. W. (2000). Scaffolds in tissue engineering bone and cartilage. Biomaterials 21, 2529-2543. doi: 10.1016/S0142-9612(00)00121-6

Hutmacher, D. W., Woodfield, T. B. F., and Dalton, P. D. (2015). "Scaffold design and fabrication," in Tissue Engineering, Second Edn, eds C. De Boer, and J. Van Blitterswijk (Oxford: Academic Press), 311-346. doi: 10.1016/b978-0-12420145-3.00010-9

Iaquinta, M. R., Mazzoni, E., Manfrini, M., D’Agostino, A., Trevisiol, L., Nocini, R., et al. (2019). Innovative biomaterials for bone regrowth. Int. J. Mol. Sci. 20:618. doi: $10.3390 /$ ijms 20030618

Jahn, S., Seror, J., and Klein, J. (2016). Lubrication of Articular Cartilage. Annu. Rev. Biomed. Eng. 18, 235-258. doi: 10.1146/annurev-bioeng-081514-123305

Karageorgiou, V., and Kaplan, D. (2005). Porosity of 3D biomaterial scaffolds and osteogenesis. Biomaterials 26, 5474-5491. doi: 10.1016/j.biomaterials.2005.02. 002

Krishnakumar, G. S., Gostynska, N., Campodoni, E., Dapporto, M., Montesi, M., Panseri, S., et al. (2017). Ribose mediated crosslinking of collagenhydroxyapatite hybrid scaffolds for bone tissue regeneration using biomimetic strategies. Mater. Sci. Eng. C 77, 594-605. doi: 10.1016/j.msec.2017.03.255

Krishnakumar, G. S., Gostynska, N., Dapporto, M., Campodoni, E., Montesi, M., Panseri, S., et al. (2018). Evaluation of different crosslinking agents on hybrid biomimetic collagen-hydroxyapatite composites for regenerative medicine. Int. J. Biol. Macromol. 106, 739-748. doi: 10.1016/j.ijbiomac.2017.08.076

Lam, C. X. F., Hutmacher, D. W., Schantz, J.-T., Woodruff, M. A., and Teoh, S. H. (2009). Evaluation of polycaprolactone scaffold degradation for 6 months in vitro and in vivo. J. Biomed. Mater. Res. Part A 90A, 906-919. doi: 10.1002/ jbm.a.32052

Leardi, R. (2009). Experimental design in chemistry: a tutorial. Anal. Chim. Acta 652, 161-172. doi: 10.1016/j.aca.2009.06.015

Lei, B., Guo, B., Rambhia, K. J., and Ma, P. X. (2019). Hybrid polymer biomaterials for bone tissue regeneration. Front. Med. 13:189-201. doi: 10.1007/s11684-0180664-6

Levingstone, T. J., Matsiko, A., Dickson, G. R., O’Brien, F. J., and Gleeson, J. P. (2014). A biomimetic multi-layered collagen-based scaffold for osteochondral repair. Acta Biomater. 10, 1996-2004. doi: 10.1016/j.actbio.2014.01.005

Li, X., Ding, J., Wang, J., Zhuang, X., and Chen, X. (2015). Biomimetic biphasic scaffolds for osteochondral defect repair. Regen. Biomater. 2, 221-228. doi: $10.1093 / \mathrm{rb} / \mathrm{rbv} 015$

Mason, B. N., Starchenko, A., Williams, R. M., Bonassar, L. J., and Reinhart-King, C. A. (2013). Tuning three-dimensional collagen matrix stiffness independently of collagen concentration modulates endothelial cell behavior. Acta Biomater. 9, 4635-4644. doi: 10.1016/j.actbio.2012.08.007

Mason, R. L., Gunst, R. F., and Hess, J. L. (2003). Statistical Design and Analysis of Experiments, 2nd Edn. New York, NY: Wiley. doi: 10.2307/2289624

Menale, C., Campodoni, E., Palagano, E., Mantero, S., Erreni, M., Inforzato, A., et al. (2019). Mesenchymal stromal cell-seeded biomimetic scaffolds as a factory of soluble RANKL in Rankl-deficient osteopetrosis. Stem Cells Transl. Med. 8, 22-34. doi: $10.1002 / \mathrm{sctm} .18-0085$

Minardi, S., Corradetti, B., Taraballi, F., Sandri, M., Van Eps, J., Cabrera, F. J., et al. (2015). Evaluation of the osteoinductive potential of a bio-inspired scaffold mimicking the osteogenic niche for bone augmentation. Biomaterials 62, 128-137. doi: 10.1016/j.biomaterials.2015.05.011

Montgomery, D. C. (2017). Design and Analysis of Experiments. New York, NY: John Wiley \& Sons, Inc. 
Montgomery, D. C., and Runger, G. C. (2003). Applied Statistics and Probability for Engineers. New York, NY: John Wiley \& Sons, Inc, doi: 10.2307/126 9738

Navarro, M., Aparicio, C., Charles-Harris, M., Ginebra, M. P., Engel, E., and Planell, J. A. (2006). Development of a biodegradable composite scaffold for bone tissue engineering: physicochemical, topographical, mechanical, degradation, and biological properties. Adv. Polym. Sci. 200, 209-231. doi: 10.1007/12_068

O’Brien, F. J. (2011). Biomaterials \& scaffolds for tissue engineering. Mater. Today 14, 88-95. doi: 10.1016/S1369-7021(11)70058-X

Pivonka, P., and Dunstan, C. R. (2012). Role of mathematical modeling in bone fracture healing. Bonekey Rep. 1:221. doi: 10.1038/bonekey.2012.221

Porter, J. R., Ruckh, T. T., and Popat, K. C. (2009). Bone tissue engineering: a review in bone biomimetics and drug delivery strategies. Biotechnol. Prog. 25, 1539-1560. doi: 10.1002/btpr.246

Puppi, D., Chiellini, F., Piras, A. M., and Chiellini, E. (2010). Polymeric materials for bone and cartilage repair. Prog. Polym. Sci. 35, 403-440. doi: 10.1016/j. progpolymsci.2010.01.006

Qiu, Z.-Y., Cui, Y., Tao, C.-S., Zhang, Z.-Q., Tang, P.-F., Mao, K.-Y., et al. (2015). Mineralized collagen: rationale, current status, and clinical applications. Materials 8, 4733-4750. doi: 10.3390/ma8084733

Rana, M., Akhtar, N., Rahman, S., Mohammad Jamil, H., and Asaduzzaman, S. M. (2017). Extraction of Hydroxyapatite from bovine and human cortical bone by thermal decomposition and effect of gamma radiation: a comparative study. Int. J. Complement. Altern. Med. 8:00263. doi: 10.15406/ijcam.2017.08. 00263

Ratner, B. D. (2013). Correlation, Materials Properties, Statistics and Biomaterials Science, Third Edn. Cambridge, MA: Academic Press. doi: 10.1016/B978-0-08087780-8.00127-3

Rault, I., Frei, V., Herbage, D., Abdul-Malak, N., and Huc, A. (1996). Evaluation of different chemical methods for cross-linking collagen gel, films and sponges. J. Mater. Sci. Mater. Med. 215-221. doi: 10.1007/BF00119733

Reháková, M., Bakoš, D., Vizárová, K., Soldán, M., and Juríc`ková, M. (1996). Properties of collagen and hyaluronic acid composite materials and their modification by chemical crosslinking. J. Biomed. Mater. Res. 30, 369-372. doi: 10.1002/(sici) 1097-4636(199603)30:3<369::aid-jbm11>3.0.co;2-f

Responte, D. J., Natoli, R. M., and Athanasiou, K. A. (2007). Collagens of articular cartilage: structure, function, and importance in tissue engineering. Crit. Rev. Biomed. Eng. 35, 363-411. doi: 10.1615/CritRevBiomedEng.v35.i5.20

Rey, C., Combes, C., Drouet, C., and Glimcher, M. J. (2009). Bone mineral: update on chemical composition and structure. Osteoporos. Int. 20, 1013-1021. doi: 10.1007/s00198-009-0860-y

Rezwan, K., Chen, Q. Z., Blaker, J. J., and Boccaccini, A. R. (2006). Biodegradable and bioactive porous polymer/inorganic composite scaffolds for bone tissue engineering. Biomaterials 27, 3413-3431. doi: 10.1016/j.biomaterials.2006.01. 039

Roy, R., Boskey, A., and Bonassar, L. J. (2010). Processing of type I collagen gels using nonenzymatic glycation. J. Biomed. Mater. Res. Part A 93, 843-851. doi: $10.1002 /$ jbm.a.32231

Roy, R., Boskey, A. L., and Bonassar, L. J. (2008). Non-enzymatic glycation of chondrocyte-seeded collagen gels for cartilage tissue engineering. J. Orthop. Res. 26, 1434-1439.

Sabir, M. I., Xu, X., and Li, L. (2009). A review on biodegradable polymeric materials for bone tissue engineering applications. J. Mater. Sci. 44, 5713-5724. doi: 10.1007/s10853-009-3770-7
Sadtler, K., Singh, A., Wolf, M. T., Wang, X., Pardoll, D. M., and Elisseeff, J. H. (2016). Design, clinical translation and immunological response of biomaterials in regenerative medicine. Nat. Rev. Mater. 1:16040. doi: 10.1038/natrevmats. 2016.40

Shankar, K. G., Gostynska, N., Montesi, M., Panseri, S., Sprio, S., Kon, E., et al. (2017). Investigation of different cross-linking approaches on 3D gelatin scaffolds for tissue engineering application: a comparative analysis. Int. J. Biol. Macromol. 95, 1199-1209. doi: 10.1016/j.ijbiomac.2016.11.010

Sheu, M. T., Huang, J. C., Yeh, G. C., and Ho, H. O. (2001). Characterization of collagen gel solutions and collagen matrices for cell culture. Biomaterials 22, 1713-1719. doi: 10.1016/S0142-9612(00)00315-X

Simon, T. M., and Jackson, D. W. (2018). Articular cartilage: injury pathways and treatment options. Sports Med. Arthrosc. 26, 146-154. doi: 10.1097/JSA. 0000000000000182

Sophia Fox, A. J., Bedi, A., and Rodeo, S. A. (2009). The basic science of articular cartilage: Structure, composition, and function. Sports Health 1, 461-468. doi: $10.1177 / 1941738109350438$

Stock, S. R. (2015). The mineral-collagen interface in bone. Calcif. Tissue Int. 97, 262-280. doi: 10.1007/s00223-015-9984-6

Sudarmadji, N., Tan, J. Y., Leong, K. F., Chua, C. K., and Loh, Y. T. (2011). Investigation of the mechanical properties and porosity relationships in selective laser-sintered polyhedral for functionally graded scaffolds. Acta Biomater. 7, 530-537. doi: 10.1016/j.actbio.2010.09.024

Tampieri, A., Celotti, G., and Landi, E. (2005). From biomimetic apatites to biologically inspired composites. Anal. Bioanal. Chem. 381, 568-576. doi: 10.1007/s00216-004-2943-0

Tampieri, A., Celotti, G., Landi, E., Sandri, M., Roveri, N., and Falini, G. (2003). Biologically inspired synthesis of bone-like composite: self-assembled collagen fibers/hydroxyapatite nanocrystals. J. Biomed. Mater. Res. 67, 618-625. doi: 10.1002/jbm.a.10039

Tampieri, A., Sandri, M., Landi, E., Pressato, D., Francioli, S., Quarto, R., et al. (2008). Design of graded biomimetic osteochondral composite scaffolds. Biomaterials 29, 3539-3546. doi: 10.1016/j.biomaterials.2008.05.008

Tampieri, A., Sprio, S., Sandri, M., and Valentini, F. (2011). Mimicking natural biomineralization processes: a new tool for osteochondral scaffold development. Trends Biotechnol. 29, 526-535. doi: 10.1016/j.tibtech.2011.04.011

Vicens-Zygmunt, V., Estany, S., Colom, A., Montes-Worboys, A., Machahua, C., Sanabria, A. J., et al. (2015). Fibroblast viability and phenotypic changes within glycated stiffened three-dimensional collagen matrices. Respir. Res. 16:82. doi: 10.1186/s12931-015-0237-z

Zhang, Y., Wang, F., Tan, H., Chen, G., Guo, L., and Yang, L. (2012). Analysis of the mineral composition of the human calcified cartilage zone. Int. J. Med. Sci. 9, 353-360. doi: 10.7150/ijms.4276

Conflict of Interest: The authors declare that the research was conducted in the absence of any commercial or financial relationships that could be construed as a potential conflict of interest.

Copyright (c) 2020 Dellaquila, Campodoni, Tampieri and Sandri. This is an openaccess article distributed under the terms of the Creative Commons Attribution License (CC BY). The use, distribution or reproduction in other forums is permitted, provided the original author(s) and the copyright owner(s) are credited and that the original publication in this journal is cited, in accordance with accepted academic practice. No use, distribution or reproduction is permitted which does not comply with these terms. 